\title{
La efectividad de los acuerdos de protección de inversiones para la atracción de inversiones extranjeras
}

Tomás Mariano Guisado Litterio*

\section{Resumen}

El presente artículo tendrá por objeto poner en tela de juicio si los acuerdos de protección de inversiones, que restringen severamente las potestades soberanas de los Estados, efectivamente atraen inversiones extranjeras en general y directas en particular, de manera que no se configuren simplemente como una carga innecesaria para el Estado que recurre a ellos. Esto, teniendo en cuenta especialmente que la idea central de aquellos tratados es promover el flujo de capitales desde países desarrollados a países en desarrollo. Luego de reseñar diferentes estudios realizados sobre el tema, puede demostrarse que no es posible establecer de forma concluyente que los acuerdos de protección de inversiones tengan o no un papel significativo en la atracción de inversiones, y que en realidad la lupa debería ponerse sobre otros factores que tienen un rol más importante para promover la inversión extranjera.

Palabras clave: acuerdos de protección de inversiones - tratados bilaterales de inversiones - inversiones extranjeras - desarrollo - flujo de capital

\section{The effectiveness of investment protection agreements in attracting foreign investments}

\begin{abstract}
This article's objective is to put into question whether investment protection agreements, while severely restricting States' sovereign powers, effectively attract foreign investments in general and direct investments in particular, so as not to become an unnecessary burden on the State that turns to them. This shall be achieved bearing in mind specifically that the central idea of these treaties is to promote the flux of capital from developed countries to developing countries. After reviewing different studies on the subject, it can be shown that it is not possible to establish in a conclusive manner that investment protection agreements do or do not have a significant role in attracting investments, and that in fact, emphasis should be placed in other factors that play a more important part in promoting foreign investment.
\end{abstract}

Key words: investment protection agreements - bilateral investment treaties - foreign investments development - capital flux

TRABAJO RECIBIDO: 03/09/2018 TRABAJO ACEPTADO: 06/11/2018

\footnotetext{
* Abogado y Maestrando en Relaciones Internacionales, Universidad de Buenos Aires (UBA, Argentina). Asesor Legal del Ministerio de Relaciones Exteriores y Culto de la República Argentina y docente e investigador de la UBA. Correo electrónico: Guisado879@ gra.derecho.uba.ar
} 


\section{Introducción}

Un acuerdo de protección de inversiones es un tratado internacional, bilateral o multilateral, cuyo objeto es otorgar una serie de garantías, tanto sustantivas como procesales, a los inversores extranjeros. En esencia, mediante estos tratados los Estados restringen sus potestades soberanas de varias formas (vgr., en cuanto a la capacidad de regular los procesos productivos y el intercambio, la posibilidad de expropiar, el sometimiento de controversias a sus propios tribunales, etc.) con el claro objetivo de posicionarse como un destino atractivo para las inyecciones de capital transnacionales.

Pese a que existen varios tratados regionales con cláusulas de protección de inversiones (entre los cuales se destaca el nuevo Tratado entre México, Estados Unidos y Canadá, próximo a reemplazar el NAFTA), los verdaderos protagonistas de la materia son los tratados bilaterales de inversiones (TBI), que ya en el año 2005 superaban los 2.500 a nivel mundial (Dolzer y Shreuer, 2008:2). En general, las inversiones extranjeras que son objeto de estos tratados son las llamadas inversiones extranjeras directas (IED), por las cuales el inversor expande sus operaciones comerciales, productivas o de servicios a otra jurisdicción, adquiriendo los activos de una explotación existente en ese país o desplegando nuevas actividades. En otras palabras, las IED se diferencian de las inversiones "de portafolio" en que en las primeras el inversor se establece de forma duradera en el Estado extranjero dotándose del control o de una participación del negocio, mientras que en las últimas el inversor se limita a adquirir títulos valores que pueden rendirle réditos o revenderlos en el futuro, como bonos del tesoro o acciones ${ }^{1}$.

Por supuesto, los riesgos asumidos por quien establece una presencia empresarial permanente en un mercado extranjero son, en general, mucho mayores que los de quienes hacen lo mismo en su propio país o quienes adquieren a distancia títulos foráneos. Es esta razón por la que se supone que los inversores directos se preocuparán especialmente porque el Estado receptor de la inversión ofrezca garantías de estabilidad y certeza, sobre todo en una época en que no son infrecuentes las "nacionalizaciones" de las empresas extranjeras por motivos que a veces no responden a más que demagogia nacionalista.

Sin embargo, las protecciones plasmadas en los tratados no siempre se limitan a que el inversor extranjero no sea discriminado con relación a sus pares domésticos, sino que muchas veces derivan en privilegios en su cabeza respecto de los demás. Estas ventajas, que pueden implicar exenciones respecto de ciertas regulaciones o cargas de aplicación general, terminan situándolo en una posición privilegiada en el mercado. El razonamiento, claro está, consiste en que este ejercicio de autocontención por parte del Estado terminará, tarde o temprano, atrayendo a aquellos inversores extranjeros que estén indagando en qué jurisdicciones tendrán un menor riesgo de que sus ganancias se vean truncadas por interferencias gubernamentales en el mercado. Por supuesto, el Estado que se somete a este sacrificio de soberanía opera bajo la presunción de que la recepción de inversiones extranjeras será conducente al desarrollo de su economía doméstica debido a la transferencia de capital y tecnología y la generación de puestos de trabajo.

Frente a esta cuestión, es relevante tener en cuenta que, a pesar de que los compromisos que los Estados asumen en los acuerdos de inversiones sean recíprocos en teoría, en la práctica se dirigen a que los países en vías de desarrollo otorguen garantías a inversores provenientes de países desarrollados, los principales exportadores de capital. De esta manera, son los países menos desarrollados quienes con mayor frecuencia se ven obligados a acatar las obligaciones estipuladas

\footnotetext{
${ }^{1}$ Foreign Direct Investment - FDI Investopedia. Disponible en https://www.investopedia.com/terms/f/fdi.asp. Consulta: 3 de mayo de 2018
} 
en los TBI. Por ejemplo, la Argentina tuvo más de cuarenta reclamos en virtud de tratados de inversiones a raíz de las políticas económicas que tomó para paliar los efectos de la crisis económica de 2001 (Skovgaard Poulsen, 2010:539-540). Es de suma importancia reflexionar acerca de en qué medida vale la pena quedar atado de pies y manos frente a una crisis como contrapartida para intentar volverse un destino seductor para las inversiones.

El presente trabajo no tendrá por objeto analizar los aspectos jurídicos de los acuerdos de protección de inversiones. Es propicio aclarar, sin embargo, a los efectos de contextualizar este estudio, que en la actualidad la totalidad del sistema que rodea a los TBI se encuentra bajo una severa crisis de legitimidad. Esta crisis no pasa solamente por la asimetría jurídica en perjuicio del Estado que se evidencia en los TBI, sino también por la muy criticada falta de transparencia en los arbitrajes inversor-Estado y la inconsistencia de la línea jurisprudencial de los tribunales, entre otras cuestiones (García, Ciko, Gauravy Hough, 2015).

En su lugar, este trabajo buscará poner en tela de juicio si estos convenios cumplen efectivamente el rol para el cual fueron concebidos, de manera que no se configuren simplemente como una carga innecesaria para el Estado que recurre a ellos. Esto, teniendo en cuenta especialmente que la idea central de aquellos tratados es promover el flujo de capitales desde países desarrollados a países en desarrollo. En otras palabras, se buscará averiguar si estos acuerdos atraen, o no, a las inversiones extranjeras en general, y directas en particular.

\section{1 - Causas y efectos de las IED}

Antes de adentrarnos en el quid del trabajo, dedicaremos unos párrafos a entender qué lleva a un emprendedor o a una empresa a invertir en el extranjero, y cuáles son las razones por las cuales un Estado se vería interesado en atraer IED, lo cual constituye la razón de ser de los TBI y es, por lo tanto, el parámetro cardinal para determinar su efectividad.

A los fines de analizar los motivos que llevan al inversor a volcar su capital en tierras foráneas, primero debe diferenciarse entre IED vertical y horizontal. La IED vertical se da cuando el inversor traslada una parte del proceso de producción de sus bienes al extranjero, y se explica desde la teoría de la ventaja comparativa. La diferencia de los costos de producción entre los países deriva en que los productores busquen "exportar" ciertos segmentos de la cadena productiva a países en donde los costos marginales relativos sean menores. De esta manera, se podrán reducir los costos abriendo en otros países filiales que se dediquen exclusivamente a la parte del proceso productivo en que puedan aprovechar una ventaja comparativa. Al analizar si esto le resulta conveniente, el empresario deberá comparar el costo que le insuma realizar esa parte de la cadena productiva en su país de origen con los gastos que le deriven llevarla adelante en el extranjero e importar lo producido (Krugman, Obstfeld y Melitz, 2016:193-195).

En la IED horizontal, el inversor reproduce en una filial ubicada en el extranjero todo el proceso productivo que realiza en su casa matriz. Esta vía será conveniente cuando el inversor quiera hacer llegar sus mercaderías a clientes extranjeros, pero necesita evitar los costos que le insumiría la exportación desde el país donde está ubicada la casa matriz (vgr. barreras arancelarias y/o paraarancelarias y costos de transporte). En estos casos, la firma podrá potenciar sus ganancias mediante la apertura de una filial que opere directamente en el país que de otra manera debería importar los bienes producidos. La IED horizontal tendrá lugar, por lo tanto, siempre que los costos marginales de producción en el país receptor de la inversión sean inferiores al costo final de producción más el costo de transporte desde el país de origen (Krugman, Obstfeld y Melitz, 2016:193-195). 
La apertura de una filial en el extranjero, tanto en casos de IED horizontal como vertical, importa la capacidad de soportar costos fijos que no suelen ser tolerables para empresas pequeñas, por lo que solamente serán rentables estas opciones para empresas que produzcan a una escala lo suficientemente grande como para que los costes fijos de mantener la filial se vean justificados por los menores costes por unidad producida (Krugman, Obstfeld y Melitz, 2016:194-200).

Cabe destacar que la IED horizontal se registra principalmente entre países desarrollados, mientras que la IED vertical tiene lugar generalmente entre éstos y los países en desarrollo. Esta última se da, especialmente, cuando se trasladan actividades intensivas en trabajo no calificado a países abundantes en trabajo y de sueldos bajos (Krugman, Obstfeld y Melitz, 2016:193-195).

En cuanto a los efectos macroeconómicos de la IED, ésta tendrá consecuencias favorables para el bienestar económico de tanto el país exportador de capital como el receptor. Las consecuencias económicas del flujo transfronterizo de capitales son análogas a aquellas que se producen a raíz de la apertura de los mercados internos al comercio internacional. Los modelos económicos ortodoxos predicen que, con la colocación de la inversión extranjera, la producción se relocaliza para aprovechar las diferencias de costos de oportunidad. Este movimiento puede, en el corto plazo, perjudicar a algunos sectores, pero ampliará la frontera de posibilidades de producción de ambos mercados a partir del incremento de las ganancias agregadas. La disminución de los costos terminará repercutiendo en la forma de una mayor producción y, en consecuencia, crecimiento económico para los países involucrados (Krugman, Obstfeld y Melitz, 2016:199-200).

Por otra parte, existe consenso en cuanto a que la llegada de inversiones deriva en el desarrollo económico del Estado receptor. Se ha dicho que "la IED es clave para el crecimiento y el progreso tecnológico de las naciones anfitrionas, especialmente en países de ingresos medios. Permite al receptor adoptar tecnología de avanzada desarrollada en otros lugares e incrementar el grado de habilidades y productividad de los trabajadores" (Bengoa, Sánchez-Robles y Shachmurove, 2017:1). De ahí que resulta relevante conocer si los TBI realmente cumplen la función de acelerar el flujo de capital entre los Estados signatarios, por sus efectos sobre el crecimiento y sobre el desarrollo económico de los países de ingresos bajos y medios.

\section{2 - Una mirada general sobre los estudios}

En una obra publicada en 2017, el académico estadounidense Michael Jacobs resumió el estado actual de la cuestión destacando la multiplicidad de estudios empíricos que se habían dispuesto a indagar en el asunto, con conclusiones dispares. Sostuvo que "estos estudios varían metodológicamente y presentan resultados conflictivos, con algunos que encontraron una relación positiva entre los TBI y el flujo de las IED hacia el mundo en desarrollo, algunos que no encontraron relación entre ambos, y otros que encontraron una relación entre TBI e IED, pero sólo en configuraciones modelo determinadas" (Jacobs, 2017:583). Jacobs divide los estudios que pasa a analizar entre aquellos que comparan el número total de TBI suscriptos y las IED recibidas y aquellos que se focalizan en los flujos de capitales entre dos países vinculados por un TBI (Jacobs, 2017:583).

El primer enfoque, que Jacobs denomina "monódico", se concentra en las señales que la firma de TBI envía a los inversores extranjeros en general, tanto aquellos cubiertos por alguno de esos TBI, como aquellos que no lo están. La lógica reside en que la asunción de estas responsabilidades importa un esfuerzo creíble para crear un ambiente amigable para los negocios, debido a los costos intrínsecamente asociados a la suscripción de TBI. Esa señal, según esta visión, lleva un gran peso en sí misma. Por esta razón, los estudios de esta clase computarán indiscriminadamente todas las inversiones extranjeras que el país reciba, independientemente de que los inversores involucrados estén cubiertos por TBI alguno (Jacobs, 2017:587). 
Debido a la disparidad de resultados, las derivaciones que pueden extraerse de este primer enfoque no son concluyentes en cuanto a que el número total de TBI suscriptos se corresponde con la cantidad total de IED recibida. Sin embargo, las falacias de esta perspectiva son evidentes: no tiene en cuenta la gran diferencia que puede significar para estas "señales" con qué países se firman los TBI (vgr. con grandes exportadores de capital o con otros importadores de capital) ni integra adecuadamente otros factores que pueden influenciar a los inversores. Por otra parte, también resulta cuestionable que un inversor no cubierto por un TBI se sienta tentado a invertir debido a estas señales, sabiéndose excluido de los beneficios que ostentarán otros inversores de diferente nacionalidad (Jacobs, 2017:587-588).

El segundo enfoque, al que Jacobs se refiere como "diádico", emplea una lógica más directa.se ocupa de cuantificar el flujo de inversiones directas desde un país desarrollado a otro en desarrollo, en situaciones en que ambos estén vinculados por un TBI. Luego de repasar los estudios que se han realizado en los últimos años empleando esta mirada, Jacobs nota que la mayoría de las investigaciones no han logrado establecer patrones estadísticamente significativos que puedan confirmar la hipótesis de que la existencia de TBI aumenta el flujo de capital entre dos Estados (Jacobs, 2017:589-590).

Aunque Jacobs entiende que este segundo método es más efectivo que el primero a la hora de extraer conclusiones (Jacobs, 2017:583), cree necesario señalar que persisten ciertas debilidades en las investigaciones de este tipo. Principalmente, no se discriminan los TBI según sus diferentes niveles de protección o las diversas garantías que ofrecen. En efecto, se los ha igualado como si el problema se redujese a una cuestión binaria, cuando la gama de diferentes TBI complejiza muchísimo la situación (Jacobs, 2017:590). Presuntamente, un inversor no se sentirá igual de atraído por un TBI que somete cualquier controversia al Centro Internacional de Arreglo de Diferencias relativas a Inversiones (CIADI) que por otro que las deja al arbitrio de los tribunales internos del Estado, por ejemplo.

\section{3 - Algunos estudios en particular}

Luego de haber realizado, de la mano del Prof. Jacobs, una mirada general sobre las investigaciones que indagaron el tema de la correlación entre TBI e IED, pasaremos a echar un vistazo más profundo sobre algunos de los estudios más destacados en términos de rigor metodológico y amplitud de muestras.

En el año 2003 la asesora del Banco Mundial Hallward-Driemeier publicó un estudio de suma importancia para la materia, en el que llegó a conclusiones de gran interés. Su investigación, siguiendo el enfoque diádico (en la terminología de Jacobs), toma de referencia el flujo bilateral de capitales desde 20 Estados miembros de la Organización para la Cooperación y el Desarrollo Económicos (OCDE) a 31 países en desarrollo entre los años 1980 y 2000, recordando que la OCDE tiene una membrecía altamente representativa del mundo desarrollado (Hallward-Driemeier, 2003:7-8). Su método consiste en analizar las variaciones en el volumen de flujo de IED entre cada par de países desarrollados y en desarrollo a partir de la entrada en vigor del TBI, incorporando diversas correcciones con el objeto de paliar los efectos de otros factores que pueden incidir conjuntamente en el aumento de las IED y de compensar los datos faltantes (Hallward-Driemeier, 2003:10-11).

Como complemento para su estudio, tomó en cuenta el grado de calidad institucional de los países en desarrollo analizados, con el objeto de inquirir qué relación tenía esta variable con respecto a los efectos de los TBI. Observó que la calidad de las instituciones internas, principalmente el respeto por el derecho a la propiedad privada, resultó predominante a la hora de atraer inversiones, y esto se reveló en que aquellos países que ya tenían instituciones sólidas tenían 
más para ganar al ratificar un TBI que aquellos que padecían precariedad institucional. De esto se desprende que "los TBI actúan más como un complemento que un sustituto para las instituciones domésticas" y que aquellos países que podrían derivar mayores beneficios de los TBI son los "que menor necesidad tienen de señalizar la calidad de sus derechos de propiedad" (Hallward-Driemeier, 2003:18-23).

La autora fue terminante en sus conclusiones, sosteniendo que hay "poca evidencia de que [los TBI] hayan estimulado IED adicional". Si bien pudo encontrar ciertas correlaciones entre TBI e IED en casos de países que gozaban de solidez institucional (por ejemplo, en el caso de Chile), estos hallazgos no llegan a ser estadísticamente relevantes. En particular, llegó al corolario de que un país de instituciones débiles no tendría éxito empleando un TBI como atajo para atraer inversiones sin implementar reformas generales a nivel interno (Hallward-Driemeier, 2003:18-23).

Frente a un panorama de creciente escepticismo respecto de la efectividad de los TBI, la Conferencia de las Naciones Unidas para el Comercio y el Desarrollo (UNCTAD) publicó en 2009 una investigación sobre el tema que nos compete, utilizando una metodología diádica. Este trabajo destacó que los incentivos para la facilitación de inversiones son solamente uno de los factores de atracción de IED, pero existen otros más importantes: el marco general de estabilidad económica, social y política del país y los componentes económicos como el tamaño del mercado, los costos de los recursos (incluyendo el trabajo) y la disponibilidad de recursos naturales (CNUCD, 2007:110).

La UNCTAD observó, en base a datos arrojados por varios estudios publicados entre 2005 y 2008, que los acuerdos de inversiones tienen cierta influencia sobre la cantidad de IED que un país en desarrollo recibe de parte de países desarrollados. Aunque estos tratados no afectan ciertas variables económicas clave, sí ejercen un efecto positivo sobre determinantes institucionales que incrementará la probabilidad de atraer IED. Esta hipótesis se vio confirmada por encuestas realizadas a empresas multinacionales, quienes mayoritariamente afirmaron que la existencia de un TBI que los favorezca "desempeña un papel" en su decisión final acerca de dónde invertir (CNUCD, 2007:110-111).

En definitiva, los resultados a los que llegó la UNCTAD afirman que los acuerdos de inversiones asisten a la atracción de inversiones mediante la mejora del factor de la calidad institucional del país en desarrollo al dotarlo de "seguridad, transparencia, estabilidad y previsibilidad". En cuanto a los factores económicos, el acuerdo sobre inversiones puede ejercer una influencia mucho mayor si no se limita a la cuestión de la protección de las inversiones, sino que forme parte de un esquema más grande de liberalización del comercio exterior. La ampliación del mercado a partir de la integración regional volverá al país un destino mucho más atractivo (CNUCD, 2007:110-111). Teniendo en cuenta estas cuestiones, la UNCTAD puso especial énfasis en que los acuerdos de inversiones "deben encontrarse embebidos en más amplias políticas de IED que cubran todos los determinantes de las inversiones extranjeras", dado que sería incorrecto buscar un vínculo monocausal entre estos tratados y el flujo de IED (CNUCD, 2007:xiii-xv).

Un muy reciente estudio a cargo de investigadores de distintas nacionalidades, publicado en diciembre de 2017, se ocupó de cuestionarse si los TBI promueven el flujo de inversiones específicamente en el caso de los países de Latinoamérica. Utilizaron como muestra el flujo de IED hacia 11 países latinoamericanos entre los años 1995 y 2012, y se valieron del enfoque que Jacobs define como monódico. Los autores toman como base que los inversores buscan países con marcos políticos y económicos sólidos, y que las instituciones consolidadas dan credibilidad a los gobiernos respecto de haber logrado y poder preservar tal ambiente. En los casos de países en desarrollo, donde las instituciones exhiben deficiencias, los acuerdos de inversiones pueden compensar estas carencias reduciendo el riesgo percibido por el inversor extranjero (Bengoa, Sánchez-Robles y Shachmurove, 2017:1-2). 
Analizando los datos, los autores notaron en lo inmediato que parece haber una asociación positiva entre cantidad de TBI y volumen de flujo de EID, pero esta relación está lejos de ser lineal. Un ejemplo muy contundente de la discontinuidad de este vínculo es el caso de Brasil, que sin tener ningún TBI en vigor, atrajo las mismas cantidades de IED que la Argentina, que es el Estado que, junto con Chile, más TBI en vigor tiene (Bengoa, Sánchez-Robles y Shachmurove, 2017:13). Por otra parte, la influencia de los TBI parece ser ínfima en economías latinoamericanas más pequeñas (como las de Paraguay, Costa Rica, Bolivia o Ecuador) debido, según los autores, a la ausencia de componentes políticos y económicos claves en estos países que aseguren su cumplimiento. En los países de mayores ingresos relativos, es particularmente notable la influencia del MERCOSUR sobre los IED, que tiene una injerencia enormemente positiva. El razonamiento, claro está, es que la existencia de dicha unión aduanera vuelve a todos los países integrantes o asociados al bloque más atractivos en virtud de las posibilidades de comercio intracomunitario. En un país que forma parte de un proceso de integración regional, al tamaño del mercado doméstico debe también sumársele el potencial para el inversor de utilizar a ese país como una plataforma para exportar a los demás miembros del bloque (Bengoa, Sánchez-Robles y Shachmurove, 2017:22-25).

El estudio llegó a la conclusión de que los acuerdos regionales de liberalización comercial, como el MERCOSUR y la ALADI tienen una influencia más importante sobre la atracción de IED que los TBI, cuya efectividad es muy escasa. Estos últimos, de hecho, resultan más útiles como herramientas geopolíticas que como imanes de inversiones. Es decir, la firma de TBI podrá servir a fines estratégicos para facilitar el acercamiento diplomático bilateral entre dos Estados, pero difícilmente tenga los efectos macroeconómicos propuestos. Siguiendo esta línea, los resultados arrojaron que los TBI carecerán de toda eficacia si el país que los firmó no tiene un nivel de estabilidad política y económica que pueda generar un ambiente de riesgos moderados para los inversores. El estudio concluye recomendando a los Estados concentrarse en forjar relaciones comerciales a largo plazo y consolidar instituciones domésticas sólidas, como principal forma de atraer IED (Bengoa, Sánchez-Robles y Shachmurove, 2017:22-25).

En un trabajo a cargo de académicos belgas publicado en 2012 se tomaron datos de 12 países de Europa Central y Oriental entre 1995 y 2009 (Colen y Guariso, 2018:8), empleando un enfoque monódico. Este estudio tiene la particularidad de discriminar el efecto de los TBI en la IED por sectores, y encontró, por ejemplo, que la correlación es mayor en actividades que requieran una alta inversión inicial de capital ${ }^{2}$ y que sean más intensivas en trabajo no calificado, particularmente la minería. En cambio, en los sectores de manufacturas se vuelve mucho más relevante el nivel de solidez institucional del país. Este panorama no es muy alentador para los partidarios de los TBI, debido a que la actividad minera contribuye en pequeña medida al desarrollo económico, en virtud de que la transferencia de conocimientos es muy escasa y de que hay una alta tasa de repatrío de las ganancias, de forma que no volverán a la economía del Estado receptor (Colen y Guariso, 2018:1214). Estas conclusiones resultan particularmente relevantes para países andinos como Bolivia, Chile y Perú, cuyas principales exportaciones son minerales.

Por otra parte, un estudio diádico del año 2009, a cargo de un investigador estadounidense, tomó como muestra el flujo de IED de 23 países desarrollados a 127 países desarrollados entre 1983 y 2001 (Kerner, 2009:83). El autor, que empleó diversos modelos para confirmar su hipótesis, afirmó categóricamente la postura de que los TBI efectivamente atraen IED, y sostuvo que otros estudios que llegaron a la conclusión contraria vieron sus resultados distorsionados por factores endógenos. Para evitar tropezar con la misma piedra, aplica a su investigación correcciones tendientes a tomar en cuenta, principalmente, el hecho de que los Estados que ya están recibiendo altas cantidades de IED se verán menos motivados a negociar TBI que aquellos que tienen mayor

\footnotetext{
${ }^{2}$ El alto nivel de inversión de capital requerido implicaría altos costos hundidos (es decir, ya incurridos y no
} recuperables) en caso de expropiación por parte del Estado. 
necesidad de atraerla. La incorporación de este factor a sus cómputos, entonces, lo lleva al resultado mencionado (Kerner, 2009:79-98).

Otro estudio diádico editado en el mismo año llegó a conclusiones diferentes. En este caso, no se buscaba analizar solamente el impacto de los TBI, sino también de los de doble imposición (TDI). Si bien los TDI pueden pretender en algunos casos lo mismo que los TBI, lo intentan de una forma muy distinta: el Estado receptor se abstiene de cobrarle al inversor impuestos sobre la misma renta que grava el Estado exportador de capital (Sachs y Sauvant, 2009:6). Los autores manifestaron la falencia de analizar el efecto de los TBI sobre la IED sin tener en cuenta la influencia de los TDI, pero terminan arribando a la conclusión de que estos últimos no tienen una influencia significativa sobre el influjo de IED, y que tampoco existe evidencia concluyente de que los TBI la tengan. No obstante, la realidad muestra que los gobiernos interesados en IED recurren regularmente a estos acuerdos con la expectativa de señalizar a los inversores un buen clima para las inversiones, funcionen o no (Sachs y Sauvant, 2009:31-32).

Por último, cabe destacar un estudio publicado en 2011 por dos investigadores estadounidenses, que empleó una metodología ingeniosa desde un enfoque monódico. En lugar de estudiar datos agregados a nivel país, se enfocaron en altos ejecutivos de diversos mercados emergentes (Brasil, India, Sudáfrica y Corea del Sur) a los que se les plantearon escenarios relativos a las inversiones para analizar cómo encararían la situación desde su firma. La idea es que las mismas personas que toman la decisión de dónde invertir sean quienes manifiesten qué tanto los TBI influyen en su decisión (Kenyon y Margalit, 2009:1-6). La encuesta arrojó que los hombres de negocios consideraban importante que el Estado en cuestión fuera parte de tratados económicos (incluyendo TBI, pero también acuerdos de libre comercio), manteniendo constantes el nivel de crecimiento económico y de estabilidad política, y el tamaño del mercado. De hecho, calificaron como más atractivo a un Estado signatario de estos acuerdos que un Estado que no lo era pero que estaba implementado reformas para la liberalización del comercio. Sin embargo, en el propio estudio se señala que las prioridades de las empresas multinacionales de los países más desarrollados pueden variar respecto de las participantes del estudio (Kenyon y Margalit, 2009:1928).

\section{Conclusión}

Pese a que no pudo establecerse concluyentemente que los acuerdos de inversiones tengan o no un papel significativo en la atracción de EID, hay algo que sí resulta claro: lo que antes no se ponía en duda, hoy está bajo un escrutinio estricto. Mientras que desde mediados de los ' 80 hasta principios de los 2000 el número de TBI creció globalmente a nivel exponencial, hoy la tendencia se invierte. A la vez que Estados como Bolivia, Ecuador y Venezuela se han retirado del CIADI con fuertes críticas y denuncias de TBI, otros países como Australia, India, Indonesia, Noruega y Sudáfrica han comenzado a renegociar sus TBI vigentes. Brasil, por su parte, llevó adelante en 2015 la firma de una nueva generación de TBI con términos mucho menos gravosos para el Estado que los acuerdos tradicionales (Arroyo Picard y Ghiotto: 2017). En los últimos tiempos, al menos 45 países y 4 organizaciones regionales han comenzado a revisar sus acuerdos vigentes, mientras algunos Estados están optando por dar por terminados los tratados existentes, en un clima de creciente desconfianza hacia los TBI (Kollamparambil, 2016).

No debe soslayarse que los TBI no son soluciones mágicas. El abanico de políticas que puede adoptar un gobierno para mejorar el influjo de IED a corto plazo es muy limitado. Los determinantes más importantes para las IED son factores económicos tales como el tamaño del mercado, la apertura al comercio exterior y la estabilidad política y, en general, ninguno de estos elementos se adquiere de un día para el otro. Son más bien el resultado de un largo proceso de 
consolidación institucional y crecimiento económico. Los TBI no parecen, en principio, un hábil sustituto de estos componentes. Más bien, aparentan tener la capacidad de potenciarlos cuando ya están presentes, pero no de suplir su rol en países que tengan ambientes hostiles a los negocios y, en especial, a la inversión extranjera (Colen y Guariso, 2018:2).

El denominador común de la generalidad de los trabajos es la fundamental importancia de las instituciones sólidas, que se plantea como un incentivo mucho más efectivo que los acuerdos de inversiones. Un empresario extranjero nunca se verá tentado a inyectar su capital en un país cuyo gobierno pueda terminar expropiando sus ganancias por rédito electoral, ni siquiera cuando las perspectivas del mercado sean sumamente alentadoras. Por otra parte, los acuerdos de libre comercio también se presentan como un factor relevante, en especial si el Estado en cuestión adopta una actitud laxa frente al comercio exterior y/o es miembro de un bloque de integración regional.

Cabe destacar que el presente trabajo puso la lupa en los presuntos efectos positivos de los TBI en cuanto a su capacidad de atraer inversiones. No obstante, los funcionarios gubernamentales no sólo deberían seguir con atención los avances producidos en las investigaciones referidas a la efectividad de los TBI, sino también contrastarlas con las desventajas propias de estos acuerdos. Muchas veces el Estado podría estar sometiéndose a estándares que en ocasiones resultan tan estrictos que restringirán intolerablemente sus prerrogativas soberanas, especialmente en lo atinente a la regulación del mercado, quedando expuestos a ser condenado internacionalmente a pagar indemnizaciones multimillonarias. Determinar cuándo valdrá la pena afrontar estos costos en busca de capital extranjero no es una tarea fácil, y no debería tomarse a la ligera.

\section{Bibliografía}

ARROYO PICARD, A. y GHIOTTO, L. (2017). Brasil y la nueva generación de Acuerdos de Cooperación y Facilitación de Inversiones: un análisis del Tratado con México, en Relaciones Internacionales, La Plata, 52, pp. 39-54. Disponible en https://revistas.unlp.edu.ar/RRII-IRI/issue/download/280/Revista\%20Completa. Consulta: 25 de noviembre de 2018

BENGOA, M.; SÁNCHEZ-ROBLES, B. y SHACHMUROVE, Y. (2017). Back to BITs and Bites: Do Trade and Investment Agreements Promote Foreign Direct Investment within Latin America? Disponible en: https://papers.ssrn.com/sol3/papers.cfm?abstract_id=3083980. Consulta: 15 de mayo de 2018

COLEN, L. y GUARISO, A. (2004). What Type of FDI Is Attracted by Bilateral Investment Treaties? Disponible en: https://ssrn.com/abstract=2400429. Consulta: 15 de mayo de 2018

CONFERENCIA DE LAS NACIONES UNIDAS PARA EL COMERCIO Y EL DESARROLLO (CNUCD) (2007). The Role of International Investment Agreements in Attracting Foreign Direct Investment to Developing Countries, United Nations Publications, Nueva York y Ginebra

DOLZER, R. y SCHREUER, C. (2008). Principles of International Investment Law, Oxford University Press, Oxford

GARCÍA, F.J.; CIKO, L.; GAURAV, A. y HOUGH, K. (2015). Reforming the International Investment Regime: Lessons from International Trade Law, en Journal of International Economic Law, Oxford, 18 (4), pp. 861-892. Disponible en: https://academic.oup.com/jiel/article/18/4/861/2357932. Consulta: 25 de noviembre de 2018

HALLWARD-DRIEMEIER, M. (2003). Do bilateral investment treaties attract foreign direct investment? Only a little bit, and they could bite, en Policy Research Working Paper, Washington, 3121 
Cuadernos de Política Exterior Argentina (Nueva Época), 128, diciembre 2018, pp. 7-16

ISSN 0326-7806 (edición impresa) - ISSN 1852-7213 (edición en línea)

JACOBS, M. (2017). Do bilateral investment treaties attract foreign direct investment to developing countries? A review of the empirical literature, en International Relations and Diplomacy, Valley Cottage, 5 (10), pp. 583-593

KENYON, T. y MARGALIT, Y. (2009). Does Joining International Treaties Attract Foreign Investment? Experimental Firm-Level Evidence. Disponible http://socsci3.tau.ac.il/ymargalit/KenyonMargalit_March_2014.pdf. Consulta: 15 de mayo de 2018

KERNER, A. (2009). Why Should I Believe You? The Costs and Consequences of Bilateral Investment Treaties, en International Studies Quarterly, Oxford, 53, pp. 73-102

KOLLAMPARAMBIL, U. (2016). Why developing countries are dumping investment treaties, The Conversation, 23 de marzo, Boston. Disponible en: http://theconversation.com/why-developing-countries-aredumping-investment-treaties-56448. Consulta: 15 de mayo de 2018

KRUGMAN, P.R.; OBSTFELD, M. y MELITZ, M. J. (2016). Economía internacional: teoría y política, 10ª ed., Pearson, Madrid

SACHS, L.E. y SAUVANT, K.P. (2009). BITs, DTTs, and FDI flows: An Overview, en SACHS, L.E. y SAUVANT, K.P., The Effect of Treaties on Foreign Direct Investment: Bilateral Investment Treaties, Double Taxation Treaties and Investment Flows, Oxford University Press, Nueva York, pp. 1-27

SKOVGAARD POULSEN, L.N. (2010). The importance of BITs for foreign direct investment and political risk insurance: revisiting the evidence, en Yearbook on International Investment Law and Policy 2009/2010, Nueva York, pp. 539-574 